GRASAS Y ACEITES 69 (4)

October-December 2018, e272

ISSN-L: 0017-3495

https://doi.org/10.3989/gya.0105181

\title{
Effects of olive oil on blood pressure: A systematic review and meta-analysis
}

\author{
F. Zamora-Zamora ${ }^{\mathrm{a}, \bowtie}$, J.M. Martínez-Galiano ${ }^{\mathrm{b}, \mathrm{c}}$, J.J. Gaforio ${ }^{\mathrm{c}, \mathrm{de,f}}$ and M. Delgado-Rodríguez ${ }^{\mathrm{b}, \mathrm{c}}$ \\ ${ }^{a}$ Paediatric Emergency Department, Hospital Complex of Jaén. Av. del Ejército Español 10; 23007 Jaén, Spain \\ ${ }^{6}$ Department of Health Sciences, Faculty of Experimental Sciences, University of Jaén, Campus las Lagunillas s/n; 23071 Jaén, Spain \\ ${ }^{\circ}$ CIBER-ESP, Instituto de Salud Carlos III, C/ Monforte de Lemos 3-5, Pabellón 11, Planta 0, 28029 Madrid, Spain \\ ${ }^{\mathrm{d}}$ Center for Advanced Studies in Olive Grove and Olive Oils. University of Jaén, Spain \\ ${ }^{e}$ Immunology Division, Department of Health Sciences, Faculty of Experimental Sciences, University of Jaén, Campus las \\ Lagunillas s/n; 23071 Jaén, Spain \\ ${ }^{\mathrm{f}}$ Agrifood Campus of International Excellence, ceiA3, Spain \\ ${ }^{\square}$ Corresponding author: francisca.zamora.sspa@juntadeandalucia.es
}

Submitted: 12 January 2018; Accepted: 22 May 2018

SUMMARY: Hypertension is one of the most important risk factors associated with the development of cardiovascular diseases. Numerous studies have revealed that a diet enriched in olive oil can have a beneficial effect on blood pressure. This systematic review includes the effects of olive oil on blood pressure in individuals without previous cardiovascular events. Liquid oil shows a decrease in blood pressure, while capsules have not produced any effect. Diastolic blood pressure decreased after the consumption of olive oil, $-0.73 \mathrm{~mm} \mathrm{Hg}, 95 \%$ CI (-1.07, $-0.40) ; p<0.001, \mathrm{I}^{2}=86.9 \%$, with high heterogeneity among the included studies. This reduction was mainly due to extra virgin olive oil (EVOO) from $10 \mathrm{ml}$ to $50 \mathrm{ml} /$ day: $-1.44 \mathrm{~mm} \mathrm{Hg}$, 95\% CI (-1.89, -1.00); $\mathrm{p}<0.001$. Regarding systolic blood pressure the observed decrease is not statistically significant. Further studies on the consumption of EVOO are needed to confirm these results.

KEYWORDS: Diastolic Pressure; Hypertension; Olive oil; Randomized Controlled Trial; Systematic review; Systolic pressure

RESUMEN: Efectos del aceite de oliva en la presión arterial: revisión sistemática y metaanálisis. La hipertensión es uno de los factores de riesgo más importantes asociados con al desarrollo de enfermedades cardiovasculares. Numerosos estudios han revelado que una dieta enriquecida en aceite de oliva puede producir un efecto beneficioso sobre la tensión arterial. En esta revisión sistemática se recogen los efectos del aceite de oliva sobre la tensión arterial en individuos sin eventos cardiovasculares previos. Es el aceite líquido el que ha mostrado los beneficios, mientras que las cápsulas no han producido ningún efecto. La tensión arterial diastólica disminuyó después del consumo de aceite de oliva, $-0.73 \mathrm{~mm} \mathrm{Hg}$, IC 95\% (-1.07, -0.40$) ; p<0.001, \mathrm{I}^{2}=86.9 \%$, con elevada heterogeneidad entre los estudios incluidos. Esta reducción se debió principalmente al aceite de oliva virgen extra (AOVE) de $10 \mathrm{ml} \mathrm{a} 50 \mathrm{ml}$ / día: $-1.44 \mathrm{~mm} \mathrm{Hg}$, IC 95\% (-1.89, -1.00); p < 0.001. En lo que se refiere a la tensión arterial sistólica el descenso producido no ha sido estadísticamente significativo. Se necesitan más estudios sobre el consumo de AOVE para confirmar estos resultados.

PALABRAS CLAVE: Aceite de oliva; Ensayo controlado aleatorizado; Hipertensión; Presión diastólica; Presión sistólica; Revisión sistemática

ORCID ID: Zamora-Zamora F https://orcid.org/0000-0002-2623-8645, Martínez-Galiano JM https://orcid. org/0000-0002-0878-8635, Gaforio JJ https://orcid.org/0000-0003-2996-9301, Delgado-Rodríguez M https://orcid. org/0000-0002-3838-2548

Citation/Cómo citar este artículo: Zamora-Zamora F, Martínez-Galiano JM, Gaforio JJ, Delgado-Rodríguez M. 2018. Effects of olive oil on blood pressure: A systematic review and meta-analysis. Grasas Aceites 69 (4), e272. https://doi. org/10.3989/gya.0105181

Copyright: (C2018 CSIC. This is an open-access article distributed under the terms of the Creative Commons Attribution 4.0 International (CC BY 4.0) License. 


\section{INTRODUCTION}

Hypertension is one of the most important risk factors associated with the development of cardiovascular disease. The threshold for the diagnosis of hypertension is a systolic blood pressure (SBP) of at least $140 \mathrm{~mm} \mathrm{Hg}$, a diastolic blood pressure (DBP) of at least $90 \mathrm{~mm} \mathrm{Hg}$, or both (Poulter et al., 2015). Hypertension increases the risk of stroke, coronary heart disease, sudden death, heart failure and peripheral arterial disease (Mancia et al., 2013). A change in lifestyle can be an effective intervention to control blood pressure. The preventive measures to adopt are restriction of salt in the diet, moderation in alcohol consumption, abundant fruit consumption, control of weight, regular physical activity, and smoking cessation (Dickinson et al., 2006).

Several epidemiological studies have analyzed the relationship between monounsaturated fatty acid (MUFA) consumption, such as olive oil, and hypertension (Alonso et al., 2006). In 2005, the OmniHeart study compared three diets: one rich in carbohydrates, another rich in vegetable proteins, and the third with MUFA. The diets rich in vegetable proteins and MUFA compared with the carbohydrate diet reduced blood pressure and improved the lipid profile (Appel et al., 2005). The International Study of Macro/ Micronutrients and Blood Pressure (INTERMAP) is a multicenter cross-sectional study of 4680 men and women in which linear regression analyses showed a significant inverse relationship between total MUFA intake and DBP. A Spanish study showed that the consumption of vegetable oleic acid, with a daily intake of $13 \mathrm{~g} /$ day, was associated with a decrease in SBP $(-0.70 \mathrm{mmHg})$ and DBP $(-0.57 \mathrm{~mm} \mathrm{Hg})$ (Miura et al., 2013). In the PREDIMED (Prevención con Dieta Mediterránea) clinical trial both SBP and DBP decreased 2.3 and $1.2 \mathrm{~mm} \mathrm{Hg}$, respectively, after one year of follow-up (Doménech et al., 2014).

The consumption of olive oil is very common in Mediterranean countries. It is associated with the Mediterranean diet and it is not clear whether the effects of olive oil are due to the oil itself or to the whole diet pattern. The objective of this study is to assess whether the consumption of olive oil reduces blood pressure in adults without previous cardiovascular events.

\section{METHODS}

\subsection{Design}

We carried out a systematic review and metaanalysis following the recommendations established by the PRISMA statement (Preferred Reporting Items for Systematic Reviews and Meta-Analyzes) (Moher et al., 2009). A systematic review protocol was developed, not registered a priori, and not modified after the beginning of the review process.

\subsection{Eligibility criteria}

We used the following inclusion criteria: a) participants: adult population with at least 18 years of age without previous cardiovascular events; $b$ ) intervention: diet enriched with olive oil for at least 12 weeks vs. diet enriched with other fat; c) outcome measures: SBP or DBP; d) design of included studies: randomized controlled trials (RCTs). We have included both healthy individuals with cardiovascular risk factors or with other non-cardiovascular pathology.

\subsection{Exclusion criteria}

We exclude studies in which the intervention was carried out in cardiovascular patients because they experience a profound change in their lifestyle, including diet, not comparable with healthy subjects or with other types of diseases. Animal studies were discarded.

\subsection{Research methods}

The following electronic databases were searched from their inception through April 10, 2018: PubMed, Embase, Cochrane plus, Web of Science, Ovid, Scopus, VHL, TDR. The language of publication was not restricted.

The search strategy was carried out through the combination of keywords related to olive oil intake (olive oil), and the different expected results: hypertension (arterial pressure, hypertension, blood pressure, DBP, SBP), and the design of adequate studies for inclusion (randomized controlled trial, systematic review, meta-analysis). Reference lists of identified original articles were searched manually. Table 1 shows the search strategy for the databases.

TABLE 1. Search strategy

\begin{tabular}{l}
\hline $\begin{array}{l}\text { PubMed, Web of Science, Embase, Ovid, Biblioteca Cochrane } \\
\text { plus, Scopus, VHL, TDR }\end{array}$ \\
\hline 1. olive oil \\
2. Arterial Pressure \\
3. Hypertension \\
4. Blood Pressure \\
5. Diastolic Pressure \\
6. Systolic Pressure \\
7. 2\# OR 3\# OR 4\# OR 5\# OR 6\# \\
8. 1\# AND 7\# \\
9. 8\# AND (Randomized Controlled Trial OR systematic \\
review OR Meta-Analysis) \\
10. $9 \#$ AND humans \\
VHL \\
1. olive oil \\
2. hypertension \\
3. Humans \\
4. 1\# AND 2\# AND 3\#
\end{tabular}




\subsection{Risk of bias in individual studies}

We used the Cochrane risk of bias tool to assess risk of bias within the following domains: selection bias, performance bias, detection bias, attrition bias, reporting bias, and other bias (Higgins and Green, 2011). Table 2 shows the studies after the validity analysis.

\subsection{Data extraction and management}

Two researchers made the selection of articles independently. Discrepancies were discussed with a third review author until consensus was reached. The following data were extracted from each study: authors, year of publication, country of implementation, duration, amount of olive oil intake in the experimental group and fat in the control one, characteristics and number of participants in each intervention applied, SBP and DBP (Table 2).

\subsection{Data synthesis}

The outcome parameter was the change in blood pressure regarding baseline values; the mean standard error of the change was computed. Mean differences (MDs) were pooled using a fixed effects model. Heterogeneity between studies results was tested using the Q test. The proportion of heterogeneity was quantified with the $\mathrm{I}^{2}$ parameter. $\mathrm{I}^{2}>50 \%$ was considered to represent considerable heterogeneity. Metarregression was performed to explore the causes of heterogeneity. We applied Egger's method to determine the possible existence of publication bias. All data were analyzed using Stata 14 SE program (College Station, TX, USA).

\section{RESULTS}

\subsection{Literature research}

The search identified 872 studies, 687 of which were identified in different databases: 119 in PubMed, 23 in Embase, 32 in the Cochrane Plus Library, 167 in the Web of Science, 35 in Ovid, 232 in Scopus, and 79 in VHL; while 185 were located through the grey literature of TDR and hand searched for references. After the exclusion of duplicates, 691 studies were evaluated. 27 studies were reviewed in full text, and 15 studies were finally included. The reasons for exclusion are detailed in Figure 1.

\subsection{Characteristics of studies included in systematic review}

Fifteen studies were included in the systematic review and meta-analysis (Kristensen et al., 2016, Rozati et al., 2015, Lee et al., 2015, Venturini et al.,
2015, Ceriello et al., 2014, Toledo et al., 2013, Singhal et al., 2013, Tapsell et al., 2013, Konstantinidou et al., 2010, Taylor et al., 2006, Rasmussen et al., 2006, Olsen et al., 2000, Ferrara et al., 2000, Prisco et al., 1998, Bonnema et al., 1995). Table 2 shows a summary of the information extracted from the included studies. The designs used by the studies were: double blind parallel RCTs (Kristensen et al., 2016, Lee et al., 2015, Singhal et al., 2013, Taylor et al., 2006, Olsen et al., 2000, Prisco et al., 1998, Bonnema et al., 1995), double-blind, randomized crossover study (Ferrara et al., 2000), and nonblinded RCTs (Rozati et al., 2015, Venturini et al., 2015, Ceriello et al., 2014, Toledo et al., 2013, Tapsell et al., 2013, Konstantinidou et al., 2010, Rasmussen et al., 2006). The follow-up ranged from 12 weeks to 4 years. The countries in which the studies were developed were Spain (Ceriello et al., 2014, Toledo et al., 2013, Konstantinidou et al., 2010), Denmark (Kristensen et al. 2016, Bonnema et al.,1995), Italy (Ferrara et al., 2000, Prisco et al., 1998), United Kingdom (Singhal et al., 2013, Taylor et al., 2006), South Korea (Lee et al., 2015), USA (Rozati et al., 2015), Brazil (Venturini et al., 2015), Australia (Tapsell et al., 2013), and two multinational studies: Denmark, United Kingdom, Sweden, Italy, Netherlands, Belgium, Russia and Norway (Olsen et al., 2000); and Finland, Denmark, Italy, Australia and Sweden (Rasmussen et al., 2006).

The fifteen studies included 6651 participants: 3358 had ingested olive oil and 3293 were fed the control diet. Four studies had more than two arms; in these studies the following branches were discarded for the present review: in the PREDIMED study the branch with Mediterranean diet plus nuts (Toledo et al., 2013), refined olive oil (Konstantinidou et al., 2010), hypocaloric diet plus fish (Tapsell et al., 2013), and pregnant women with fewer weeks of administration (Olsen et al., 2000). Venturini et al., (2015) gives their outcomes as mean and interquartile range and they could not be included in meta-analysis. Men and women were pooled in the analyses.

The participants were adults without cardiovascular events. Some participants had cardiovascular risk factors such as overweight or obesity (Rozati et al., 2015, Tapsell et al., 2013, Taylor et al., 2006), diabetes mellitus (Ceriello et al., 2014), incipient or established diabetic nephropathy (Lee et al., 2015, Bonnema et al., 1995) or more than three cardiovascular risk factors (Toledo et al., 2013), hypertension (Ferrara et al., 2000, Prisco et al., 1998), metabolic syndrome (Venturini et al., 2015) and psoriatic arthritis (Kristensen et al., 2016). Three studies were performed in healthy adults (Singhal et al., 2013, Konstantinidou et al., 2010, Rasmussen et al., 2006). Olsen et al., (2000) recruited twin pregnancies and pregnancy induced hypertension. 


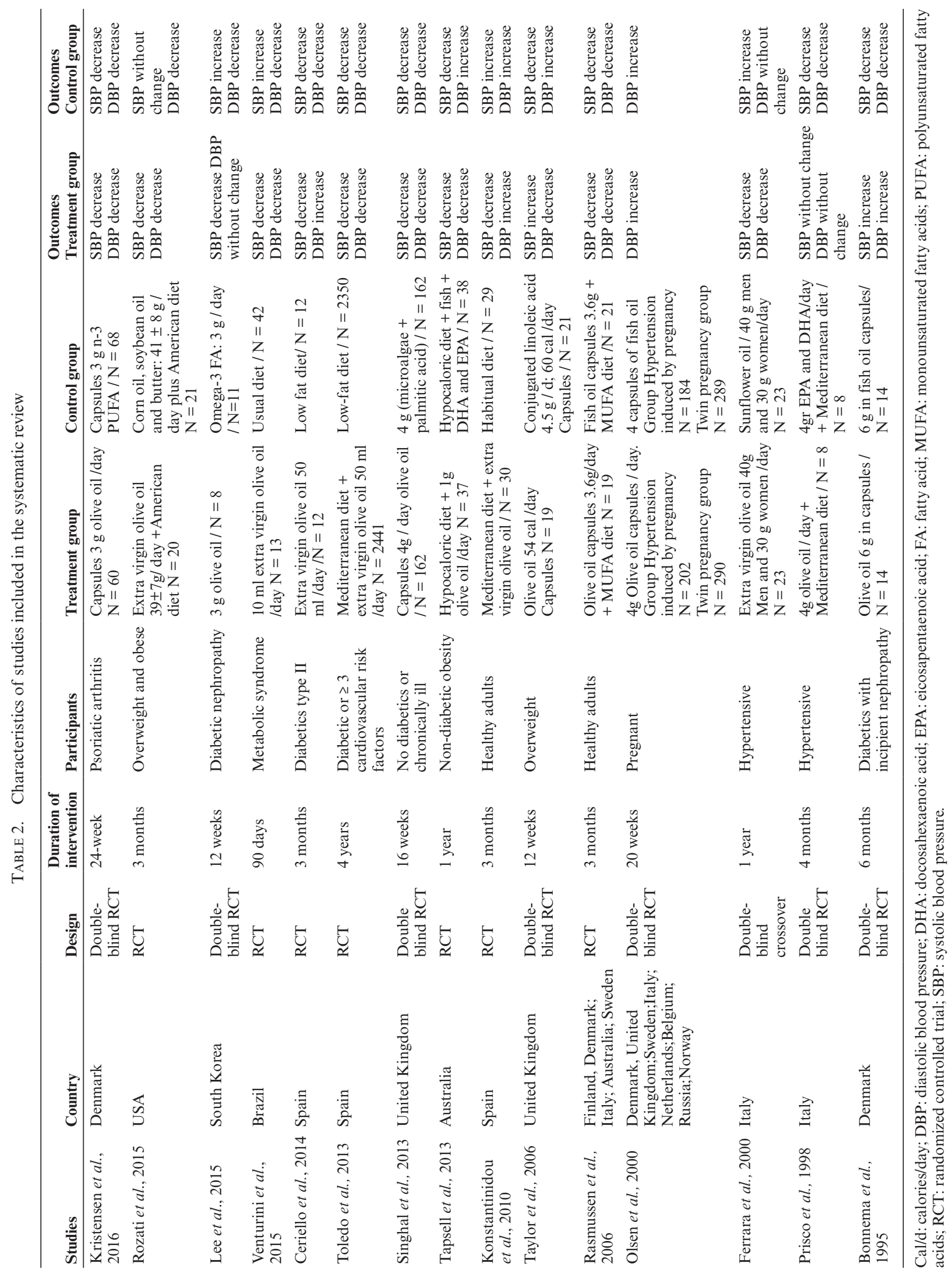




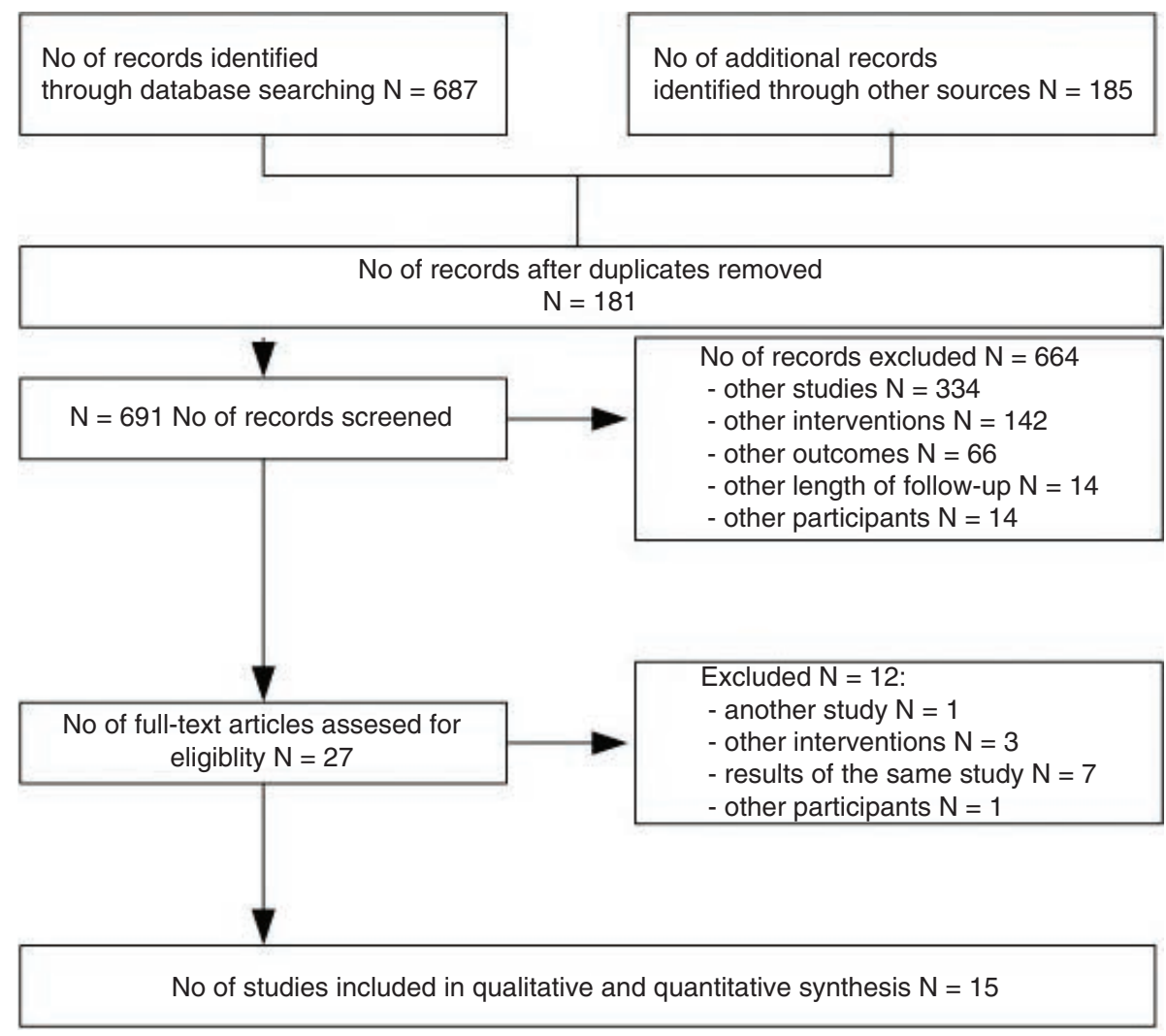

FIGURE 1. Flow chart of study procedure. Randomized controlled studies of at least three months duration, not developed in animals, or in individuals with previous cardiovascular events have been included. Other interventions have been excluded, such as the administration of other non-ingested supplements or the intake of two oils together at the same time.

\subsection{Types of interventions}

The olive oil was administered in capsules of $1-6 \mathrm{~g} /$ day (Kristensen et al., 2016, Lee et al., 2015, Singhal et al., 2013, Tapsell et al., 2013, Taylor et al., 2006, Rasmussen et al., 2006, Olsen et al., 2000, Prisco et al., 1998, Bonnema et al., 1995), and in liquid form as extra virgin olive oil (EVOO) from $10 \mathrm{ml}$ to $50 \mathrm{ml} /$ day (Rozati et al., 2015, Venturini et al., 2015, Ceriello et al., 2014, Toledo et al., 2013, Ferrara et al., 2000, Konstantinidou et al., 2010), in the context of different types of diets, such as the American diet (Rozati et al., 2015), or the Mediterranean diet (Konstantinidou et al., 2010, Toledo et al., 2013, Prisco et al., 1998). The studies that supplemented liquid oil provided it as EVOO, while the studies with capsule supplement provided it with olive oil.

The control groups took both capsules, liquid oil, habitual diet and low-fat diet. The controls took capsules with different fatty acids: microalgae and palmitic acid (Singhal et al., 2013), conjugated linoleic acid (Taylor et al., 2006), docosahexaenoic acid (DHA) and eicosapentaenoic acid (EPA) (Kristensen et al., 2016, Lee et al., 2015, Tapsell et al., 2013, Bonnema et al., 1995, Rasmussen et al., 2006, Olsen et al., 2000, Prisco et al., 1998). In liquid form the next fats were administered to the control groups: corn oil, soybean oil and butter (Rozati et al., 2015), and sunflower oil (Ferrara et al., 2000). Finally, in four studies, no supplement was provided to the control groups: habitual diet (Venturini et al., 2015, Konstantinidou et al., 2010), and low fat diet (Ceriello et al., 2014, Toledo et al., 2013).

The diet administered was adequate to the energy requirements, except in Tapsell et al., (2013) who administered a hypocaloric diet with 1750 (SD 417) $\mathrm{kcal}$ and 1600 (SD 355) kcal in the olive oil and control groups, respectively. Physical activity was not restricted in the included studies; they were requested to maintain their regular routine of physical activity. Tapsell et al., (2013), recommended walking for 30-minutes three days a week, with similar results among groups.

\subsection{Outcome measures}

Fourteen studies assessed DBP and SBP, and one study only DBP (Olsen et al., 2000). No adverse events were mentioned: only nine participants in the n-3 polyunsaturated fatty acid (PUFA) supplemented group and six participants in the olive oil group reported mild gastrointestinal adverse effects in Kristensen et al., (2016). 


\subsection{Risk of bias in individual studies}

We used the Cochrane risk of bias tool (Higgins and Green, 2011) to assess all studies for their risk of bias within the following domains: selection bias, performance bias, detection bias, attrition bias, reporting bias, and other bias. Figure 2 provides an overview of the risk of bias assessment. Two studies had high risk for selective reporting bias (Venturini et al., 2015, Olsen et al., 2000) and one study was classified as high risk for attrition bias (Tapsell et al., 2013). An intention-to-treat analysis was performed. The included studies were considered as having low risk for bias.

\subsection{Results of the meta-analysis}

Olive oil did not decrease SBP more than other fat, MDs $=-0.11$, CI $95 \%(-0.68,0.46), \mathrm{I}^{2}=85.1 \% ; p$ heterogeneity $<0.001$. The studies dispensed liquid olive oil or capsules. To identify the effect of the two kinds of supplementation meta-analysis was stratified by this variable (capsules and oil) (Figure 3): no significant effect was observed either for capsules or liquid on SBP.

Olive oil showed a significant decrease in DBP with a fixed effects model of $-0.73 \mathrm{~mm} \mathrm{Hg}, 95 \%$ CI $(-1.07,-0.40) ; p<0.001 ; \mathrm{I}^{2}=84.5 \%$; $p$ heterogeneity $<0.001$. This effect was mainly due to liquid

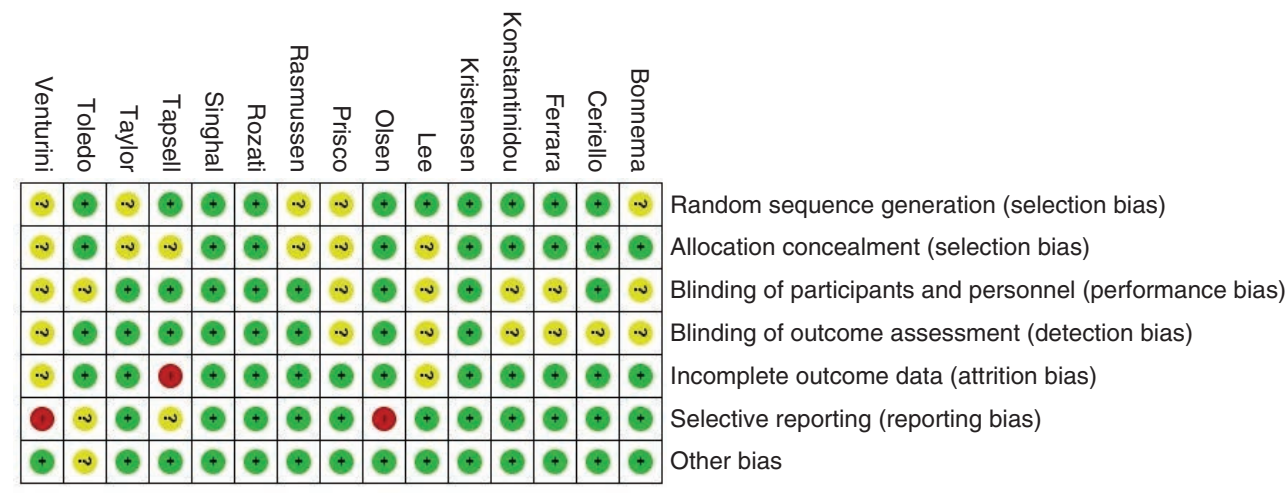

FIGURE 2. Risk of bias. For each study, each domain of bias is indicated as: low risk of bias in green, unclear risk of bias in yellow, and high risk of bias, in red.

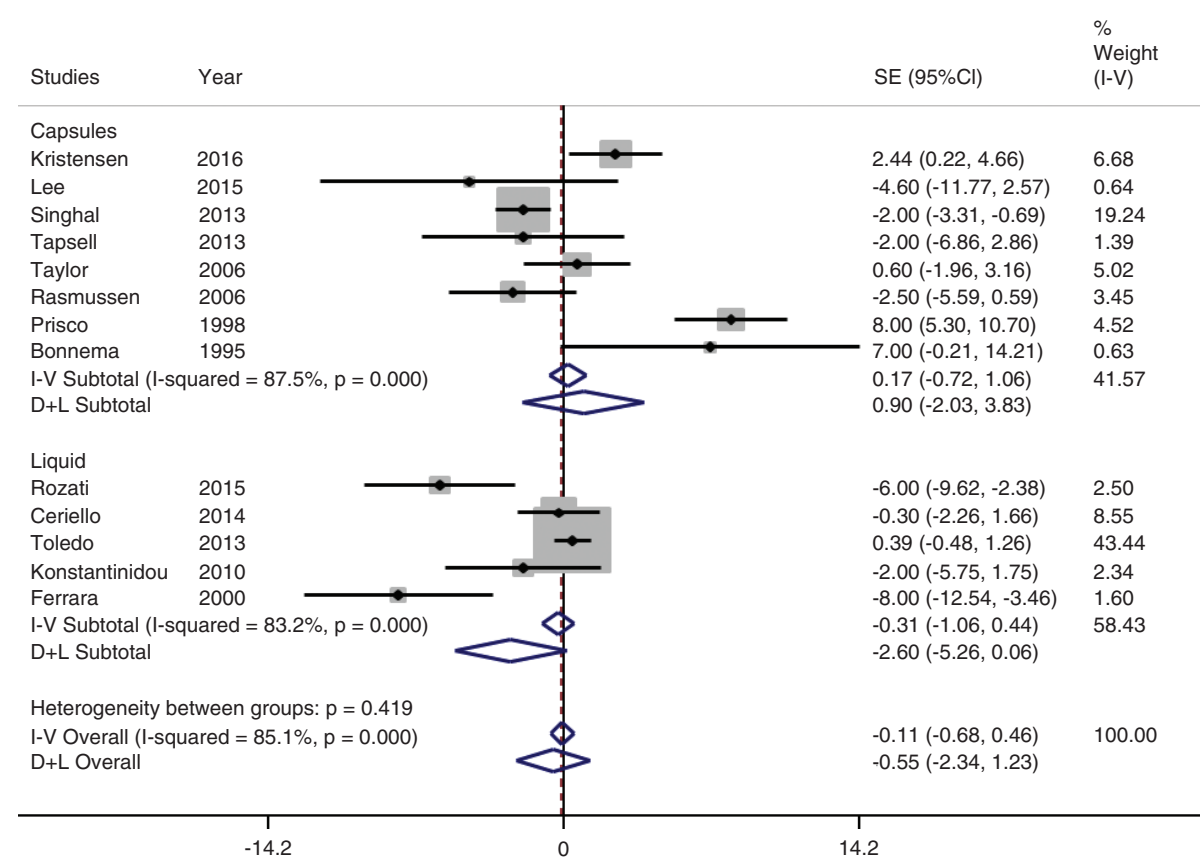

FIGURE 3. Meta-analysis of the effect of olive oil on systolic blood pressure, stratified by type of supplementation. The mean standard error of the change was computed. For each study, the shaded square represents the point estimate of the intervention effect. The individuals who have taken olive oil are located to the left of the forest plot. 


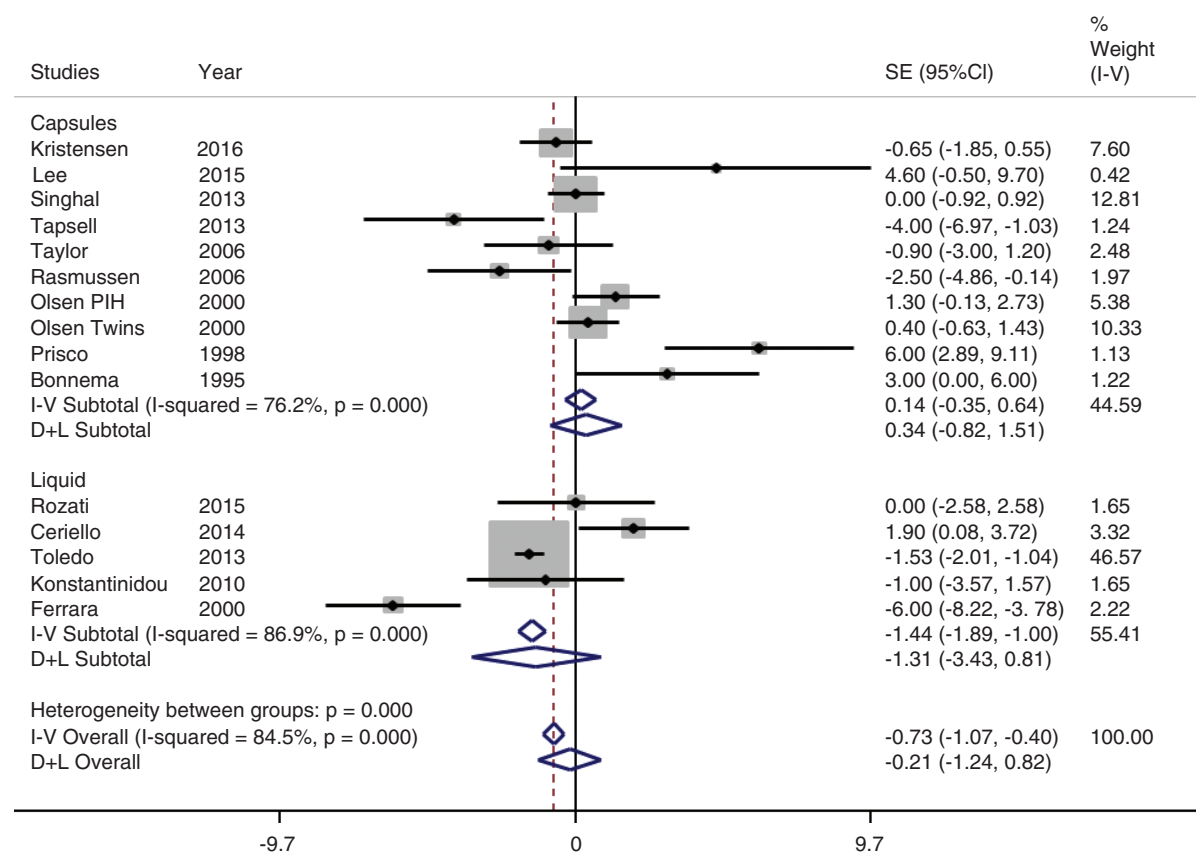

FiguRE 4. Meta-analysis of olive oil on diastolic blood pressure, stratified by type of supplementation. The mean standard error of the change was computed. For each study, the shaded square represents the point estimate of the intervention effect. The individuals who have taken olive oil are located to the left of the forest plot.

oil EVOO: a reduction of $-1.44 \mathrm{~mm} \mathrm{Hg}, 95 \% \mathrm{CI}$ $(-1.89,-1.00) ; \mathrm{p}<0.001$; with a high heterogeneity, $\mathrm{I}^{2}=86.9 \% ; p$ heterogeneity $<0.001$. The olive oil in capsules had no significant influence on DBP, $0.14 \mathrm{~mm} \mathrm{Hg}, 95 \%$ CI $(-0.35,0.64), \mathrm{I}^{2}=76.2 \%, p=$ 0.5 (Figure 4). A meta-regression was performed to inquire the causes of heterogeneity. Neither the quantity of grams of olive oil on SBP $(p=0.35)$ or $\operatorname{DBP}(p=0.51)$, nor the year of publication $(p=0.27$ and $p=0.70$, respectively), seem to be the cause of the heterogeneity found among the studies selected for the meta-analysis. Among the causes of heterogeneity are the different diets, and the characteristics of the patients for whom the studies were developed.

\subsection{Risk of bias across studies (publication bias)}

Egger's method showed $p$ values of 0.67 and 0.23 for SBP and DBP, respectively.

\section{DISCUSSION}

In this systematic review of 6651 participants without previous cardiovascular events in 15 RCTs, comparing a diet enriched with olive oil versus a diet enriched with other fats, a significant reduction in DBP was observed, with high heterogeneity. This heterogeneity may be due to differences in the diets of control groups, characteristics of the populations (very different countries, with different risk factors, etc.), and the type of supplementation of olive oil. The EVOO seems to be the main factor responsible for the decrease in DBP. The PREDIMED trial
(Toledo et al., 2013) is the more influential study in the pooled results with a weight of $43.44 \%$ and $46.57 \%$ for SBP and DBP, respectively, and with more of the $70 \%$ of all subjects. The use of a random effects model implies giving a higher weight for much smaller studies, and more prone to bias than the PREDIMED. That is the reason we relied on the fixed effects model.

Considering the individual studies, a higher decrease in SBP was obtained with liquid EVOO, about $40 \mathrm{~g}$ in men and $30 \mathrm{~g}$ in women, compared to sunflower oil (Ferrara et al., 2000): $-8 \mathrm{~mm} \mathrm{Hg}$ in SBP, CI 95\% (-12.5, -3.46), and $-6 \mathrm{~mm} \mathrm{Hg}$ in DBP, CI $95 \%(-8.22,-3.78)$. In another study (Rozati et al., 2015), EVOO (39 \pm 7 g/day) significantly reduced SBP in $-6 \mathrm{~mm} \mathrm{Hg}, 95 \%$ CI $(-9.62,-2.38)$, when compared with corn oil, soybean oil and butter together in an American diet. A lower reduction was observed with olive oil capsules $(4 \mathrm{~g})$ versus capsules of microalgae and palmitic acid: $-2 \mathrm{~mm} \mathrm{Hg}$ in SBP, $95 \%$ CI $(-3.31,-0.69)$ (Singhal et al., 2013). In the PREDIMED trial after 3.8 years of followup (Toledo et al., 2013), liquid EVOO decreased DBP by $-1.53 \mathrm{~mm} \mathrm{Hg}, 95 \%$ CI $(-2.01,-1.04)$. This reduction is similar to that found with olive oil capsules, compared to capsules containing fish oil (Rasmussen et al., 2006), $-2.5 \mathrm{~mm} \mathrm{Hg}$ in DBP, $95 \%$ CI (-4.86, -0.14), and lower than reported in obese subjects (Tapsell et al., 2013): $-4 \mathrm{~mm} \mathrm{Hg}$ in DBP, 95\% CI (-6.97, -1.03).

The study by Venturini et al., (2015), which could not be pooled as a mean difference could not be obtained, observed interesting results comparing 
EVOO with a regular diet in participants with metabolic syndrome. They reported a decrease in the mean SBP of $-5 \mathrm{~mm} \mathrm{Hg}$ and $-14 \mathrm{~mm} \mathrm{Hg}$ in DBP.

Other studies with interventions of shorter duration than 12 weeks, not included in this review, showed significant reductions in blood pressure. In a double-blind crossover trial of 24 women, Moreno Luna et al., (2012) examined the influence of oil with high content in polyphenols on blood pressure: EVOO reduced SBP by $-7.91 \pm 9.51 \mathrm{~mm}$ $\mathrm{Hg}$ and DBP $-6.65 \pm 6.63 \mathrm{~mm} \mathrm{Hg}$. These effects are similar to those observed in a systematic review on the effect of first-line antihypertensive drugs choice (Wright and Musini, 2009). The effect of polyphenols has also been evaluated in a group of 160 healthy men from the North, Center and South of Europe (Bondia-Pons et al., 2007) in a randomized cross-over trial with three intervention periods: 25 $\mathrm{ml} /$ day of olive oil were administered with different concentrations of polyphenols. Both SBP and DBP decreased after consuming olive oil for nine weeks. In addition, the properties of virgin olive oil were evaluated in the SOLOS study in 40 men with stable coronary disease (Fitó et al., 2005): SBP decreased after the intake of EVOO $(p<0.001)$, with no change in DBP. A systematic review on the effects of virgin olive oil polyphenols found significant differences in SBP and no effect on DBP (Hohmann et al., 2015), although the number of pooled subjects is small, 69 .

Olive oil seems to inhibit the activity of angiotensin-converting enzymes, and blocks the binding to angiotensin II receptor, and this hypotensive activity was demonstrated in studies on animals or humans (Patten et al., 2016).

Among the strengths of this study is the exhaustive search developed without language restriction, the number of studies reviewed, and the quality of the included studies. The results could be extended to healthy subjects, with cardiovascular risk factors, type 2 diabetes, hypertension, overweight, obesity, and countries with distinct economic and social development. The main limitation of our systematic review is the heterogeneity among the studies. It could be justified because some studies have been carried out in areas with regular consumption of olive oil and it is possible that the group control has also taken olive oil. In addition, some participants have taken antihypertensive treatment for their underlying disease, thus decreasing the potential benefit of olive oil. Toledo et al., 2013, developed a study on individuals with different cardiovascular risk factors, including hypertension for which they need antihypertensive therapy, although the individuals were distributed into similar percentages between the intervention and control groups, $1666(68 \%)$ patients in the extra virgin olive oil group and 1666 $(70.9 \%)$ in the control group. Likewise, in Ferrara et al., 2000, did a randomized crossover study in which there were basic conditions for all individuals. At the end of the follow-up, daily drug dosage was significantly reduced in the EVOO group, and $34.7 \%$ needed no antihypertensive therapy, while all patients required treatment during the sunflower oil diet. Physical activity may also vary among different populations.

Nevertheless, we consider that the number of studies on olive oil and blood pressure is still small. The intake of EVOO of between 10-50 ml per day can reduce diastolic blood pressure in healthy individuals or those with cardiovascular risk factors, even in hypertensive patients, and can be an important therapeutic tool. Further studies on EVOO are needed to reduce heterogeneity and consolidate the results.

\section{CONCLUSIONS}

The present meta-analysis provides evidence for a beneficial effect of EVOO on blood pressure in participants without cardiovascular events. Healthy individuals or those with cardiovascular risk factors can benefit from a reduction in DBP if they consume olive oil for at least three months.

\section{REFERENCES}

Alonso A, Ruiz-Gutiérrez V, Martínez-González MA. 2006. Monounsaturated fatty acids, olive oil and blood pressure: epidemiological, clinical and experimental evidence. Public Health Nutr. 9, 251-257. https://doi.org/10.1079/ PHN2005836

Appel LJ, Sacks FM, Carey VJ, Obarzanek E, Swain JF, Miller ER 3rd, Conlin PR, Erlinger TP, Rosner BA, Laranjo NM, Charleston J, McCarron P, Bishop LM; OmniHeart Collaborative Research Group. 2005. Effects of protein, monounsaturated fat, and carbohydrate intake on blood pressure and serum lipids: results of the OmniHeart randomized trial. JAMA 294, 2455-2564. https://doi. org/10.1001/jama.294.19.2455

Bondia-Pons I, Schroder H, Covas MI, Castellote AI, Kaikkonen J, Poulsen HE, Gaddi AV, Machowetz A, Kiesewetter H, Lopez-Sabater MC. 2007. Moderate consumption of olive oil by healthy European men reduces systolic blood pressure in non-Mediterranean participants. J. Nutr. 137, 84-87. https://doi.org/10.1093/jn/137.1.84

Bonnema SJ, Jespersen LT, Marving J, Gregersen G. 1995 Supplementation with olive oil rather than fish oil increases small arterial compliance in diabetic patients. Diabetes Nutr. Metab. 8, 81-87.

Ceriello A, Esposito K, La Sala L, Pujadas G, De Nigris V, Testa R, Bucciarelli L, Rondinelli M, Genovese S. 2014. The protective effect of the Mediterranean diet on endothelial resistance to GLP-1 in type 2 diabetes: a preliminary report. Cardiovasc. Diabetol. 13, 140. https://doi. org/10.1186/s12933-014-0140-9

Dickinson HO, Mason JM, Nicolson DJ, Campbell F, Beyer FR, Cook JV, Williams B, Ford GA. 2006. Lifestyle interventions to reduce raised blood pressure: a systematic review of randomized controlled trials. J. Hypertens. 24, 215-233. https://doi.org/10.1097/01.hjh.0000199800.72563.26

Doménech M, Roman P, Lapetra J, García de la Corte FJ, Sala-Vila A, de la Torre R, Corella D, Salas-Salvadó J, Ruiz-Gutiérrez V, Lamuela-Raventós RM, Toledo E, Estruch R, Coca A, Ros E. 2014. Mediterranean diet reduces 24-hour ambulatory blood pressure, blood glucose, and lipids: one-year randomized, clinical 
trial. Hypertension 64, 69-76. https://doi.org/10.1161/ HYPERTENSIONAHA.113.03353

Ferrara LA, Raimondi AS, d'Episcopo L, Guida L, Dello Russo A, Marotta T. 2000. Olive oil and reduced need for antihypertensive medications. Arch. Intern. Med. 160, 837-842. https://doi.org/10.1001/archinte.160.6.837

Fitó M, Cladellas M, de la Torre R, Marti J, Alcántara M, Pujadas-Bastardes M, Marrugat J, Bruguera J, LopezSabater MC, Vila J, Covas MI; members of the SOLOS Investigators. 2005. Antioxidant effect of virgin olive oil in patients with stable coronary heart disease: a randomized, crossover, controlled, clinical trial. Atherosclerosis 181, 149158. https://doi.org/10.1016/j.atherosclerosis.2004.12.036

Higgins JPT, Green S (editors). 2011. Cochrane Handbook for Systematic Reviews of Interventions Version 5.1.0 [updated March 2011]. The Cochrane Collaboration.

Hohmann CD, Cramer H, Michalsen A, Kessler C, Steckhan N, Choi K, Dobos G. 2015. Effects of high phenolic olive oil on cardiovascular risk factors: A systematic review and meta-analysis. Phytomedicine 22, 631-640. https://doi. org/10.1016/j.phymed.2015.03.019

Konstantinidou V, Covas MI, Muñoz-Aguayo D, Khymenets O, de la Torre R, Sáez G, Tormos M del C, Toledo E, Marti A, Ruiz-Gutiérrez V, Ruiz Méndez MV, Fito M. 2010. In vivo nutrigenomic effects of virgin olive oil polyphenols within the frame of the Mediterranean diet: a randomized controlled trial. FASEB J. 24, 2546-2557. https://doi. org/10.1096/fj.09-148452

Kristensen S, Schmidt EB, Schlemmer A, Rasmussen C, Lindgreen E, Johansen MB, Christensen JH. 2016. The effect of marine $n-3$ polyunsaturated fatty acids on cardiac autonomic and hemodynamic function in patients with psoriatic arthritis: a randomised, double-blind, placebocontrolled trial. Lipids Health Dis. 15, 216. https://doi. org/10.1186/s12944-016-0382-5

Lee SM, Chung SH, Park Y, Park MK, Son YK, Kim SE, An WS. 2015. Effect of Omega-3 Fatty Acid on the Fatty Acid Content of the Erythrocyte Membrane and Proteinuria in Patients with Diabetic Nephropathy. Int. J. Endocrinol. 2015, 208121. https://doi.org/10.1155/2015/208121

Mancia G, Fagard R, Narkiewicz K, Redon J, Zanchetti A, Bohm M, Christiaens T, Cifkova R, Backer GD, Dominiczak A, Galderisi M, Grobbee DE, Jaarsma T, Kirchhof P, Kjeldsen SE, Laurent S, Manolis AJ, Nilsson PM, Ruilope LM, Schmieder RE, Sirnes PA, Sleight P, Viigimaa M, Waeber B, Zannad F; Grupo de Trabajo para el manejo de la hipertensión arterial de la Sociedad Europea de Hipertensión (ESH) y la Sociedad Europea de Cardiología (ESC). 2013. Guía de práctica clínica de la ESH/ESC 2013 para el manejo de la hipertensión arterial. Rev. Esp. Cardiol. 66, e1-e64. https://doi.org/10.1016/j. recesp.2013.07.016

Miura K, Stamler J, Brown IJ, Ueshima H, Nakagawa H, Sakurai M, Chan Q, Appel LJ, Okayama A, Okuda N, Curb JD, Rodriguez BL, Robertson C, Zhao L, Elliott P; INTERMAP Research Group. 2013. Relationship of dietary monounsaturated fatty acids to blood pressure: the International Study of Macro/Micronutrients and Blood Pressure. J. Hypertens. 31, 1144-1150. https://doi. org/10.1097/HJH.0b013e3283604016

Moher D, Liberati A, Tetzlaff J, Altman DG; PRISMA Group. 2009. Preferred reporting items for systematic reviews and meta-analyses: the PRISMA statement. PLoS Med. 6, e1000097. https://doi.org/10.1371/journal.pmed.1000097

Moreno-Luna R, Muñoz-Hernández R, Miranda ML, Costa AF, Jiménez-Jiménez L, Vallejo-Vaz AJ, Muriana FJ, Villar
J, Stiefel P. 2012. Olive oil polyphenols decrease blood pressure and improve endothelial function in young women with mild hypertension. Am. J. Hypertens. 25, 1299-1304. https://doi.org/10.1038/ajh.2012.128

Olsen SF, Secher NJ, Tabor A, Weber T, Walker JJ, Gluud C. 2000. Randomised clinical trials of fish oil supplementation in high risk pregnancies. Fish Oil Trials in Pregnancy (FOTIP) Team. BJOG 107, 382-395. https:// doi.org/10.1111/j.1471-0528.2000.tb13235.x

Patten GS, Abeywardena MY, Bennett LE. 2016. Inhibition of Angiotensin Converting Enzyme, Angiotensin II Receptor Blocking, and Blood Pressure Lowering Bioactivity across Plant Families. Crit. Rev. Food Sci. Nutr. 56, 181-214.

Poulter NR, Prabhakaran D, Caulfield M. 2015. Hypertension. Lancet 386, 801-812. https://doi.org/10.1016/S01406736(14)61468-9

Prisco D, Paniccia R, Bandinelli B, Filippini M, Francalanci I, Giusti B, Giurlani L, Gensini GF, Abbate R, Neri Serneri GG. 1998. Effect of medium-term supplementation with a moderate dose of n-3 polyunsaturated fatty acids on blood pressure in mild hypertensive patients. Thromb. Res. 91, 105-112. https://doi.org/10.1016/S0049-3848(98)00046-2

Rasmussen BM, Vessby B, Uusitupa M, Berglund L, Pedersen E, Riccardi G, Rivellese AA, Tapsell L, Hermansen K; KANWU Study Group. 2006. Effects of dietary saturated, monounsaturated, and n-3 fatty acids on blood pressure in healthy subjects. Am. J. Clin. Nutr. 83, 221-226. https://doi. org/10.1093/ajen/83.2.221

Rozati M, Barnett J, Wu D, Handelman G, Saltzman E, Wilson T, Li L, Wang J, Marcos A, Ordovás JM, Lee YC, Meydani M, Meydani SN. 2015. Cardio-metabolic and immunological impacts of extra virgin olive oil consumption in overweight and obese older adults: a randomized controlled trial. Nutr. Metab. (Lond). 12, 28. https://doi.org/10.1186/ s12986-015-0022-5

Singhal A, Lanigan J, Storry C, Low S, Birbara T, Lucas A, Deanfield J. 2013. Docosahexaenoic acid supplementation, vascular function and risk factors for cardiovascular disease: a randomized controlled trial in young adults. $J$. Am. Heart Assoc. 2, e000283. https://doi.org/10.1161/ JAHA.113.000283

Tapsell LC, Batterham MJ, Charlton KE, Neale EP, Probst YC, O'Shea JE, Thorne RL, Zhang Q, Louie JC. 2013. Foods, nutrients or whole diets: effects of targeting fish and LCn3PUFA consumption in a $12 \mathrm{mo}$ weight loss trial. BMC Public Health 13, 1231. https://doi. org/10.1186/1471-2458-13-1231

Taylor JS, Williams SR, Rhys R, James P, Frenneaux MP. 2006. Conjugated linoleic acid impairs endothelial function. Arterioscler. Thromb. Vasc. Biol. 26, 307-312. https://doi. org/10.1161/01.ATV.0000199679.40501.ac

Toledo E, Hu FB, Estruch R, Buil-Cosiales P, Corella D, SalasSalvadó J, Covas MI, Árós F, Gómez-Gracia E, Fiol M, Lapetra J, Serra-Majem L, Pinto X, Lamuela-Raventós RM, Sáez G, Bulló M, Ruiz-Gutiérrez V, Ros E, Sorli JV, Martínez-González MA. 2013. Effect of the Mediterranean diet on blood pressure in the PREDIMED trial: results from a randomized controlled trial. BMC Med. 11, 207. https://doi.org/10.1186/1741-7015-11-207

Venturini D, Simão AN, Urbano MR, Dichi I. 2015. Effects of extra virgin olive oil and fish oil on lipid profile and oxidative stress in patients with metabolic syndrome. Nutrition 31, 834-840. https://doi.org/10.1016/j.nut.2014.12.016

Wright JM, Musini VM. 2009. First-line drugs for hypertension. Cochrane Database Syst. Rev. 3, CD001841. https://doi. org/10.1002/14651858.CD001841.pub2 